\title{
CLOUDS BASED TECHNOLOGICAL BUSINESS ENGINEERING
}

\author{
Dr. Alexander Gromoff ${ }^{1}$, Nikolay Kazantsev ${ }^{2}$, Mikhail Ponfilenok $^{3}$, Julia Stavenko ${ }^{4}$ \\ ${ }^{1}$ National Research University "Higher School of Economics", str. Myasnitskaya 20, Moscow; \\ alexander.gromoff@me.com \\ ${ }^{2}$ National Research University "Higher School of Economics", str. Myasnitskaya 20, Moscow; \\ nkazantsev@hse.ru \\ ${ }^{3}$ National Research University "Higher School of Economics", str. Myasnitskaya 20, Moscow; \\ ponfilenok@hse.ru \\ ${ }^{4}$ National Research University “Higher School of Economics”, str. Myasnitskaya 20, Moscow; \\ ystavenko@hse.ru
}

\section{Keywords}

Business architecture, Enterprise architecture (EA), Subject-oriented Business Process Management (S-BPM), SOA, Real-time Business Architecture (RBA), Cloud Computing, SOA 2.0, BigData center.

\section{EXTENDED ABSTRACT}

Nowadays there are various views on the future of business architecture. On the one hand, it's getting strongly influenced by IT: information flows are growing rapidly and walls between the departments or even sub-companies are dissolving or at least start to fade. On the other hand, business architecture incumbents are not often ready for quick e-transformations due to their silos: inner friction, employees and "as-is" processes. The scope of the new range of architecture seems to be an interdisciplinary combination of the approaches and is getting out of concept layer. In this study an analysis of co-adoption of several modern concepts of the new enterprise architecture creation- real-time business processes generation on the global cloud-based self-generated business service basis is provided.

The feedback loop makes business processes as visible for corrections as locally efficient. The architecture itself takes the responsibility for the global efficiency and strategy goals achievement. The main obstacle for such business development or reengineering on a platform of basic or referential patterns is a 'human factor', which is a key issue in resource usage for such processes.

SOA, it seems, had an ability to overcome threshold of human factor nihilism. Nowadays, when "SOA" term is mentioned, professionals interpret it as IT architecture with a fixed set of integrated services. Since "fixed" is a key issue here due to standardization and cost saving strategies, the question of responding to business agility trend is one of the most vital for SOA today.

The concept of real-time business architecture is in charge of rapid changes of business requirements (Gromoff et al., 2012). Numerous authors suggested an alternative view on business modeling using free services in order to meet variable business demands by means of creating the prototype of app store - is-store in network where services of various vendors are collected and simultaneous feedback from the users, who attached their personal experience (rating), is received.

In this work the advanced view on the topic is provided with an attempt to install a virtual SOA torrent that catches services from the Internet and makes them available to customers. The attempt to unite technical and management approaches in business architecture solving flexibility problem was impossible several years ago, when technical possibilities of service-oriented architecture were not able to allow its serious projections on managerial tasks.

The state-of-the-art for today's technological facilities of the BigData centers, which are growing faster than mushrooms in the rainbow forest, has started a unique process of dictating new mental paradigm for traditional business mentalities. NOW we have to understand that not only referential models of business processes, or even executable blocks of business units, can be simply bought from Clouds traders, but much more, something that has always been considered as a main assets of any business - expertise and intellectual capital. This futuristic reality of automated business 
engineering could be considered as an approach to the newer business vision, which is dictated by modern technological abilities and tendencies.

In this respect it's easy to see that in such business architecture only strategic targeting and monitoring is a responsibility of the true human executive level while the rest is compiled automatically from patterns and basics, best practices, and concepts 'as to be best'. In the final phase of business orchestration intellectual resources are selected from Clouds and after legal formalities are switched into action of the ready-to-go processes.

In addition, it seems that the problem of process impediment by human factor has been finally solved, since now the Process itself is selecting useful and adoptive human/intellectual resource for further utilization.

\section{REFERENCES}

Boh, W. F., \& Yellin, D. (2007). Using Enterprise Architecture Standards in Managing Information Technology. Journal of Management Information Systems / Winter 2006-7, Vol. 23, No. 3, 163- 207.

Braun, C., \& Winter, R. (2005). A Comprehensive Enterprise Architecture Metamodel and Its Implementation Using a Metamodeling Platform. Proceedings of Enterprise Modelling and Information Systems Architectures, Proc. of the Workshop in Klagenfurt, 64-79. Klagenfurt.

Gromoff, A., Chebunidze, K. (2005). Knowledge retrieve as a basis of business management. Information Technologies In Design And Production, №3, pp.23-35.

Chebotarev, V., \& Gromoff, A. (2011). Technology of innovative activities of the enterprise. National research University - "Higher School of Economics" (HSE) - Letters 2, pp. 101-109.

Dietz, J., \& Hoogervorst, J. (2011). A critical investigation of TOGAF. Lecture Notes on Business Information Processing (LNBIP) no. 79. http://dx.doi.org/10.1007/978-3-642-21058-7_6

Fleischmann, A. (2010). What Is S-BPM? S-BPM ONE - Setting the Stage for Subject-Oriented Business Process Management. B Communications in Computer and Information Science. Heidelberg: Springer Berlin. http://dx.doi.org/10.1007/978-3-642-15915-2_7

Forecast analysis: Enterprise Application Software Worldwide, 2009-2014, 3 Q10 update, Gartner; URL www.gartner.com.

Gromoff , A., Kozhevnikov, D. (2011). Instruments Of Centaur-System Approach To Organization Modeling. Information Technologies In Design And Production(2).

Gromoff, A., Chebotarev, V. (2010). BPM Approach Evolution. Business Informatics(1).

Gromoff, A., Chebotarev, V., Evina, K., \& Stavenko, Y. (2011). An Approach to Agility in Enterprise Innovation S-BPM One Learning by Doing. Doing by Learning Third International Conference.

Gromoff, A., Chebotarev, V., Evina, K. (2011). An Approach to Agility in Enterprise Innovation. S-BPM ONE - LEARNING BY DOING - Springer Berlin. (213), pg. 271-280. http://dx.doi.org/10.1007/978-3642-23471-2 19

Gromoff, A., Evina, K., Kozhevnikov, D., Ponfilenok, M., Kazantsev, N. (2012). Modern era in business architecture Design. Mapping the global future: evolution through innovation and excellence. Proccedings of 14th Annual International conference. New York: Global Business And Technology Association. pg. 208-215

Gromoff, A., Stavenko, J., Evina, K., Kazantsev, N. (2012). An enterprise search in unstructured data in ECM using S-BPM approach. Proceedings of the 10th Int. Workshop on Modeling, Simulation, Verification and Validation of Enterprise Information Systems, MSVVEIS 2012 and 1st Int. Workshop on , WEBI 2012,in Conj. with ICEIS 2012, pg. 94-105 


\section{AUTHORS' BIOGRAPHIES}

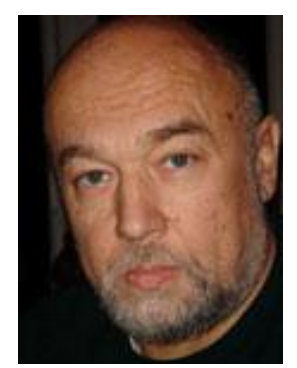

Alexander Gromoff was educated in Moscow Physical-Engineering Institute; obtained PhD from Moscow State University in 1983; later worked as a system analyst in different branches and from 1993 has focused on business process analysis. Established successful consultancy firm "Con-vera" in the fields of ECM and BPM project management. In 2005 was invited by National Research University 'Higher School of Economics' as Professor of BPM Chair, and since 2007 had been a Chairman of BPM at Business Informatics Department of the University. Currently is the Professor and Chairman of BPM practice, as well Director of Science \& Education Center of 'Information Control Technologies'. Latest works and publications dedicated to the topics: enterprise architecture, innovation process management, subject-orientated modeling and process management, operational risk management, enterprise content management, entropy based business process maintenance, semantic content analysis. 